\section{INFORMAL PATIENTS DETAINED}

DeAR Sir,

Dr Chiswick is correct in saying that data are not automatically sent to the Mental Welfare Commission on the use of consecutive Section 31 recommendations which do not lead to a Section 24 nor on the use of Section 31 recommendations for informally admitted residents (Joumal, November 1979, 135, 482-3).

Indeed there is no statutory provision at all for informing the Commission when Section 31 is used and, although many of our colleagues do so, this is entirely of their own volition and we appreciate it.

The Commission have no doubt but that such detention should carry with it a statutory obligation to notify them, and also that there should be a statutory limit on the number of occasions when the Section 31 procedure is consecutively used in respect of the same detention.

We have for long been concerned that a patient could be detained for an indefinite period by the use of consecutive Section 31 recommendations that this procedure does not have to be accounted for to anyone.

As $\mathrm{Dr}$ Chiswick says, there is a strong argument for its correction, and we have reason to believe that many of our senior colleagues in Scotland hold the same view.

HM Medical Commissioners,

A. N. M. Brittain Mental Welfare Commission for Scotland, 22 Melville Street, Edinburgh EH3 7 NS

Dear Sir,

Dr Derek Chiswick rightly points out (Joumal, November 1979, 135, 482-3) that we did not give the number of Section 31 reclassifications from informal status in our analysis of compulsory admissions (Joumal, August 1979, 135, 104-14). These data, inter alia, were lost during attempts to comply with editorial exhortations for brevity. In the decade 1963-72 there were 187 such reclassifications, representing 22 per cent of all Section $31 \mathrm{~s}$ during that period; the annual mean in the first six years was 10.6 compared with 30.7 in the last four years. Dr Chiswick quotes 38 per cent for the Royal Edinburgh Hospital in his own recent study.

We agree with Dr Chiswick that the use of consecutive Section $31 \mathrm{~s}$ is at variance with the intention of law makers although in many cases the time needed to contact the nearest relative and the family doctor before submitting the documents to the
Sheriff may make a second seven days order essential. We would support any steps which might be taken in a review of the Scottish legislation to discourage such a practice and agree that the Mental Welfare Commission might be the appropriate body to monitor the use of Section 31 more strictly.

Our inability to find published evidence of dissatisfaction with the use of Section 31 was meant to be a factual statement and not a defence, spurious and ostrich-like or otherwise. Dr Chiswick's suggestion that patients subject to detention find difficulty in voicing their complaints may be true, but does not explain why there has been considerable public criticism and disquiet over the similar aspects of the Act in England and Wales.

The intention of our paper was to describe the operation of the Act as we found it but not to defend any particular practice. We welcome any comments and comparisons as part of the general debate in the period leading up to Review of the Scottish Act.

W. A. EuLuT

G. C. TIMBury

M. WALKER

Area Alcoholism Unit,

Sunnyside Royal Hospital,

Montrose D D10 97P

\section{MICROCOMPUTERS IN PSYCHIATRY}

Dear Sir

It is with deep regret that we learn of the death of Dr Christopher Evans, psychologist and computer scientist at the National Physics Laboratory. We feel it appropriate briefly to document the 'state of the art' in the applications of the microcomputer in psychiatry-applications that Dr Evans did much to foster and develop. From his recent television series"The Mighty Micro"-and his book of the same name, it is evident that his death came just at the start of the decade that will realise many of his ideas.

The development. of the microprocessor 'chip' in the early part of the 1970's has brought the cost of computer systems down to $£ 5,000$ or less, making them an economic proposition for clinical and research workers in the NHS.

Although there are ethical difficulties in the widespread use of computers, most of these do not apply to the small, self-contained microcomputers on which Dr Evans did most of his work. In his method, the patient is asked questions on a TV screen and answers directly on a keyboard-this technique where there is no intermediary between patient and 'machine being called 'interactive'. Dr Evans, in 1973, showed that patients were quite content to sit at a computer and answer questions about their symptoms. He later demonstrated (1977) 